\title{
Mutational analysis of AXIN2, MSX1, and PAX9 in two Mexican oligodontia families
}

\author{
Y.D. Mu ${ }^{1,2}$, Z. Xu ${ }^{1}$, C.I. Contreras ${ }^{1}$, J.S. McDaniel ${ }^{1}$, K.J. Donly ${ }^{1}$ and \\ S. Chen ${ }^{1}$ \\ ${ }^{1}$ Department of Developmental Dentistry, Dental School, \\ University of Texas Health Science Center, San Antonio, Texas, USA \\ ${ }^{2}$ Stomotology Department, Sichuan Provincial People's Hospital, Chengdu, \\ Sichuan, China \\ Corresponding author: S. Chen \\ E-mail: Chens0@uthscsa.edu
}

Genet. Mol. Res. 12 (4): 4446-4458 (2013)

Received July 4, 2012

Accepted May 15, 2013

Published October 10, 2013

DOI http://dx.doi.org/10.4238/2013.October.10.10

\begin{abstract}
The genes for axin inhibition protein 2 (AXIN2), msh homeobox 1 (MSX1), and paired box gene 9 (PAX9) are involved in tooth root formation and tooth development. Mutations of the AXIN2, MSX1, and PAX9 genes are associated with non-syndromic oligodontia. In this study, we investigated phenotype and AXIN2, MSX1, and PAX9 gene variations in two Mexican families with non-syndromic oligodontia. Individuals from two families underwent clinical examinations, including an intra-oral examination and panoramic radiograph. Retrospective data were reviewed, and peripheral blood samples were collected. The exons and exon-intronic boundaries of the AXIN2, MSX1, and PAX9 genes were sequenced and analyzed. Protein and messenger RNA structures were predicted using bioinformative software programs. Clinical and oral examinations revealed isolated non-syndromic oligodontia in the two Mexican families. The average number of missing teeth was 12 . The sequence analysis of exons and exon-intronic regions of AXIN2, MSX1, and PAX9 revealed 11 singlenucleotide polymorphisms (SNPs), including seven in AXIN2, two
\end{abstract}


in MSX1, and three in PAX9. One novel SNP of MSX1, c.476T $>\mathrm{G}$ (Leu159Arg), was found in all of the studied patients in the families. MSX1 Leu159Arg and PAX9 Ala240Pro change protein and messenger RNA structures. Our findings suggested that a combined reduction of MSX1 and PAX9 gene dosages increased the risk for oligodontia in the Mexican families, as in vivo investigation has indicated that interaction between Msx1 and Pax9 is required for tooth development.

Key words: AXIN2; MSX1; PAX9; Single-nucleotide polymorphisms; Oligodontia

\section{INTRODUCTION}

Agenesis of permanent teeth is one of the most common craniofacial congenital anomalies, with an overall incidence ranging from 1 to $9 \%$ of the population if missing 3rd molars are excluded (Schalk-van der Weide et al., 1992; Stockton et al., 2000; Gabris et al., 2001). Oligodontia is defined as the absence of six or more teeth excluding 3rd molars. Tooth development is regulated by epithelial-mesenchymal interactions and their reciprocal molecular signals. These interactions involve a complex network of numerous molecules including growth factors and transcription factors (Thesleff and Sharpe, 1997). Although the etiology of tooth agenesis is not fully understood, studies in humans and mice have demonstrated over 200 candidate genes that are active in tooth development (Nieminen et al., 1998).

Currently, three mutations of the axin inhibition protein 2 (AXIN2), msh homeobox 1 (MSX1), and paired box gene 9 (PAX9) genes are often associated with tooth agenesis. Mutations in the AXIN2 gene cause oligodontia as well as a predisposition to colorectal cancer (Lammi et al., 2004). AXIN2 plays a critical role in the regulation of beta-catenin stability in the Wnt signaling pathway. Human AXIN2 mutations associated with oligodontia have been reported (Lammi et al., 2004; Mostowska et al., 2006a; Bergendal et al., 2011). The MSX1 and PAX9 genes encode homeodomain transcription factors expressed in the mesenchyme during the initial stages of dental development in response to epithelial signals (Mackenzie et al., 1991; Neubuser et al., 1995). Studies have also shown that MSX1 and PAX9 gene mutations are associated with tooth agenesis (Vastardis et al., 1996; Stockton et al., 2000; van den Boogaard et al., 2000; Frazier-Bowers et al., 2002; Lidral and Reising, 2002; Das et al., 2003; De Muynck et al., 2004; Jumlongras et al., 2001, 2004; Klein et al., 2005; Chishti et al., 2006; Kapadia et al., 2006; Kim et al., 2006; Tallon-Walton et al., 2007; Bergendal et al., 2011; Suda et al., 2011). Because the symptoms in two Mexican families studies were similar to those of non-syndromic oligodontia, we hypothesized that mutations of the AXIN2, MSX1, and PAX9 genes were associated with these cases. In the present study, we characterized the phenotype and performed mutational analysis of these three genes through sequencing analysis of the coding and adjacent intronic regions in two Mexican families with isolated non-syndromic oligodontia.

\section{MATERIAL AND METHODS}

\section{Patients}

Two Mexican families with oligodontia were enrolled in this study to sequence the 
AXIN2, MSX1, and PAX9 genes. The subjects were pediatric patients of the Department of Developmental Dentistry at the Dental School of the University of Texas Health Science Center at San Antonio (Texas, USA). The participants, and their parents if necessary, signed informed consent forms. The protocol of the study was reviewed and approved by the ethics committee of University of Texas Health Science Center at San Antonio. Physical and dental examinations were carried out on 11 individuals from the families. Pedigree construction was carried out through interviews and clinical examinations (Figure 1). An intra-oral examination was performed to assess the presence of teeth, tooth sizes, tooth morphology, and enamel abnormalities. Panoramic radiographs of available family were taken to assess dental development. Extra- and intra-oral pictures of the probands were taken. A thorough clinical examination of other tissues of ectodermal origin, including the skin, hair, nails, sweat glands, ears, and eyes, was carried out.

Family 1

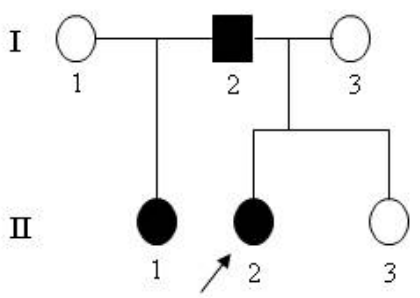

Family 2

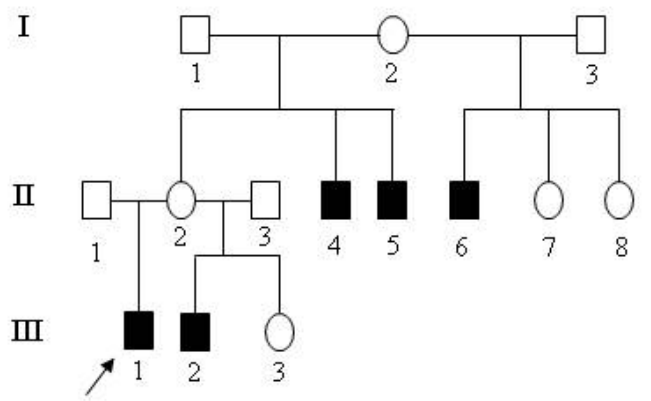

Figure 1. Pedigrees of the 2 oligodontia families studied. Arrows indicate the probands of each family. Filled squares $/$ circles $=$ affected; open squares $/$ circles $=$ unaffected; squares $=$ males; circles $=$ females.

\section{DNA sequencing analysis}

Peripheral blood samples were collected from 10 family members (four in family 1 and six in family 2) and 50 healthy Mexicans as negative controls. Genomic DNA was extracted from whole blood using a Wizard Genomic DNA Purification Kit (Promega, Madison, WI, USA), Polymerase chain reaction (PCR) was used to amplify the coding exons and adjacent intronic sequences of the AXIN2, MSX1, and PAX9 genes. The primer sequences and annealing temperatures used to amplify the three genes are listed in Tables 1-3. PCR amplification products were analyzed on 1\% agarose gels and purified using a QIAquick PCR Purification Kit (Qiagen Inc., Valencia, CA, USA). DNA sequencing was performed at the University of Texas at Austin Institute for Cellular and Molecular Biology core facilities (USA). Sequencing results and consensus sequences from the National Center for Biotechnology Information human genome database were compared using the SeqManII program from the Lasergene package (DNAStar Inc., Madison, WI, USA). Mutation description followed the nomenclature recommended by the Human Genomic Variation Society. 
Table 1. AXIN2 primer sequences.

\begin{tabular}{|c|c|c|c|}
\hline \multicolumn{2}{|c|}{ Primer sequence $\left(5^{\prime}-3^{\prime}\right)$} & \multirow{2}{*}{$\frac{\text { Size }(b p)}{498}$} & \multirow{2}{*}{$\frac{\text { Annealing temperature }\left({ }^{\circ} \mathrm{C}\right)}{53}$} \\
\hline Exon $2 \mathrm{a}$ & F: TTGAGGAGTTGAAAAGCCTGT & & \\
\hline Exon $2 \mathrm{a}$ & R: CTTGATCGCCCAATAAGGAG & & \\
\hline Exon $2 b$ & F: AGCGCTATGTTGGTGACTTG & 604 & 53 \\
\hline Exon $2 b$ & R: CCCCACTCCTCACATATTCG & & \\
\hline Exon $2 \mathrm{c}$ & F: CCTGCCACCAAGACCTACAT & 491 & 55 \\
\hline Exon $2 \mathrm{c}$ & R: CATGGCCAGCAGTCCTAACT & & \\
\hline Exon 3 & F: GCTTTCTGCCCAGGTGAG & 396 & 57 \\
\hline Exon 3 & R: TACATGCACAGGTGCGGTCT & & \\
\hline Exon 4 & F: GATGATTGATGGGCAGGATT & 401 & 53 \\
\hline Exon 4 & R: CCCTATACCTCTCCCCATTCC & & \\
\hline Exon 5 & F: CTACACCCGAACATGGGTTT & 355 & 53 \\
\hline Exon 5 & R: CACATGCGCACACCCTAAC & & \\
\hline Exon 6 & F: GTAGGGAGCCGAATGTTGC & 710 & 53 \\
\hline Exon 6 & R: TGCCGCCCTCTTAGAAACTA & & \\
\hline Exon 7 & F: GCCGCATTACAGGCATTTAG & 530 & 53 \\
\hline Exon 7 & R: GTGGTCTGCTCAGTCCAACG & & \\
\hline Exon 8 & F: GGCACTGACCCCTGTTCAT & 501 & 53 \\
\hline Exon 8 & R: TCTTCTCATGGGAGGGTTTG & & \\
\hline Exon 9 & F: CCACTGTTAACCCAGGGTCTT & 406 & 56 \\
\hline Exon 9 & R: CAACATCTACGTTTACTGTTCCTCA & & \\
\hline Exon 10 & F: TGCTAAACTTGTTCCATTCCA & 368 & 52 \\
\hline Exon 10 & R: TGAGCAAACAAACTGAGAGCA & & \\
\hline Exon 11 & F: CCTCAGTCCTCCATGTTGGT & 478 & 56 \\
\hline Exon 11 & R: AGGCAGCATCTTCAATAGCC & & \\
\hline
\end{tabular}

Table 2. MSX1 primer sequences.

\begin{tabular}{llccc}
\hline Primer sequence $\left(5^{\prime}-3^{\prime}\right)$ & Size $(\mathrm{bp})$ & Annealing temperature $\left({ }^{\circ} \mathrm{C}\right)$ & Reagents added \\
\hline Exon 1 & F: CTGGCCTCGCCTTATTAGC & 766 & 58 & $5 \%$ DMSO \\
Exon 1 & R: GCCTGGGTTCTGGCTACTC & & 56 & $2 \%$ DMSO \\
Exon 2 & F: ACTTGGCGGCACTCAATATC & 698 & & \\
Exon 2 & R: CAGGGAGCAAAGAGGTGAAA & & & \\
\hline
\end{tabular}

Table 3. PAX9 primer sequences.

\begin{tabular}{llcc}
\hline Primer sequence $\left(5^{\prime}-3^{\prime}\right)$ & Size $(\mathrm{bp})$ & Annealing temperature $\left({ }^{\circ} \mathrm{C}\right)$ \\
\hline Exon 2 & F: CCACTGAGGCGGTGCGGAAAG & 227 & 58 \\
Exon 2 & R: CCTACAACTTGTAGGAACACGAGCAAAG & \\
Exon 3a & F: AGGCAGCTGTCCCAAGCAGCG & 235 \\
Exon 3a & R: TGTATCGCGCCAGGATCTTGCTG & 58 \\
Exon 3b & F: ATCCGACCGTGTGACATCAGCC & 239 \\
Exon 3b & R: GGAGGGCACATTGTACTTGTCGC & 345 \\
Exon 3c & F: GCATCTTCGCCTGGGAGATCCG & 58 \\
Exon 3c & R: GAGCCCCTACCTTGGTCGGTG & 263 \\
Exon 4 & F: TTTGGGTCCCGTCTCAAGAGTGG & \\
Exon 4 & R: CCTAAATCCCGCCGCCACG & 450 & 58 \\
Exon 5 & F: GGAGAGTAGAGTCAGAGCATTGCTG & & 58 \\
Exon 5 & R: GAGACCTGGGAATTGGGGGA & & 58
\end{tabular}

\section{Bioinformatics analysis of AXIN2, MSX1, and PAX9 protein and messenger RNA (mRNA) structures}

Single-nucleotide polymorphisms (SNPs) were analyzed with populations (http:// www.ncbi.hlm.nih.gov/SNP). Possible amino acid substitutions in protein structure or 
changes in function were predicted with two web server tools: PolyPhen (http://genetics.bwh. harvard.edu/pph/) and SIFT (http://www.blocks.fhcrc.org/sift/SIFT.html). Computational two-dimensional models of AXIN2, MSX1, and PAX9 proteins were constructed with the bioinformatics tool DNASIS v2.5. Secondary structures of the full-length AXIN2, MSX1, and PAX9 mRNAs were predicted using the program GeneBee (http://www.genebee.msu. su/genebee.html).

\section{Statistical analysis}

Data analysis with the chi-square test was used to determine significant differences in the number of missing teeth.

\section{RESULTS}

\section{Phenotype analysis}

Clinical and oral examinations revealed no birth defects such as orofacial cleft, craniofacial malformation, or colorectal disease. No ectodermal abnormalities of nails, hair, skin, or sweat glands were present in the 11 individuals examined in the families, indicating an isolated non-syndrome oligodontia. Pedigree analysis is shown in Figure 1.

Six of the 8 affected members in the families revealed multiple missing teeth (Table 4). In family 1 , three affected individuals had absent permanent 1 st and 2 nd molars in all four quadrants to various degrees in addition to missing premolars and incisors, whereas in family 2, only subject III:1 lacked two mandibular 1st molars; other affected members had mainly missing premolars or incisors. For the 3rd molars, subjects II:2 in family 1 as well as III:1 and III:2 in family 2 were too young to confirm. Excluding 3rd molars, the average number of missing teeth was 14 in family 1 , and the average number of missing teeth was 7 in family 2. Figure 2A-D shows the panoramic radiographs and extra-oral and intra-oral photographs of the probands from the families.

\begin{tabular}{|c|c|c|c|c|c|c|c|c|c|c|c|c|c|c|c|c|c|}
\hline & & \multicolumn{8}{|c|}{ Right } & \multicolumn{8}{|c|}{ Left } \\
\hline & & 8 & 7 & 6 & 5 & 4 & 3 & 2 & 1 & 1 & 2 & 3 & 4 & 5 & 6 & 7 & 8 \\
\hline \multirow[t]{6}{*}{ F1 } & II:1 Max & * & & & * & * & & * & & & * & & * & * & & & * \\
\hline & Mand & * & $*$ & & * & & & * & & & * & & & * & & $*$ & * \\
\hline & II:2 Max & ? & * & & * & * & & * & & & * & & * & * & $*$ & & ? \\
\hline & Mand & $?$ & * & * & * & & & & * & * & & & & * & * & * & ? \\
\hline & I:1 Max & * & * & & * & * & & * & & & & & & * & & * & * \\
\hline & Mand & * & * & & * & & & & * & * & & & * & * & & * & * \\
\hline \multirow[t]{6}{*}{$\mathrm{F} 2$} & III:1 Max & ? & & & * & & & * & & & * & & & * & & & ? \\
\hline & Mand & ? & & * & * & & & & * & * & & & & & $*$ & & ? \\
\hline & III:2 Max & $?$ & & & * & & & * & & & * & & & * & & & ? \\
\hline & Mand & $?$ & & & & & & * & * & * & & & & & & & ? \\
\hline & II:4 Max & * & & & & & & & * & * & & & & & & & * \\
\hline & Mand & * & & & & & & & & & & & & & & & * \\
\hline
\end{tabular}

II:1, II:2, I:1 in family 1 and III:1, III:2, II:4 in family $2 . *$ Congenitally missing teeth; ? = impossible diagnosis for young age patient. $\mathrm{F} 1=$ Family $1 ; \mathrm{F} 2=$ family 2 ; Max $=$ maxilla; Mand $=$ mandibles. 
Family 1 II : 2
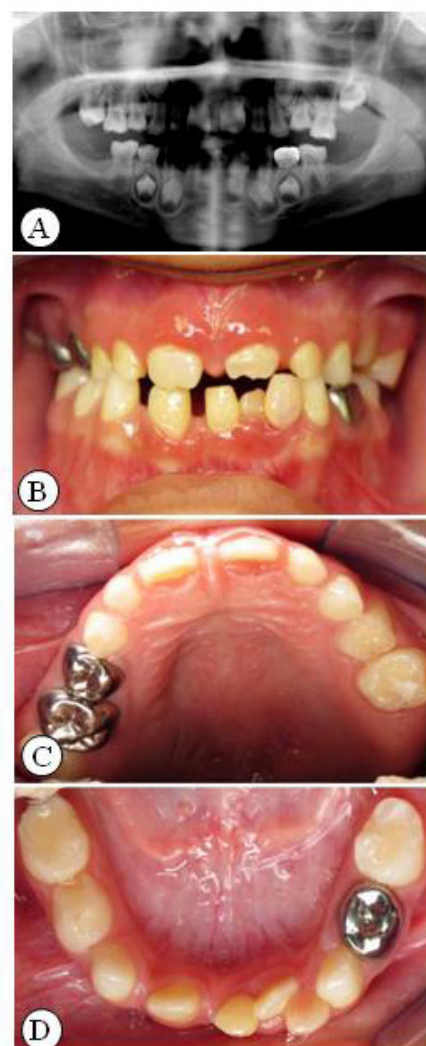

Family 2 III : 1
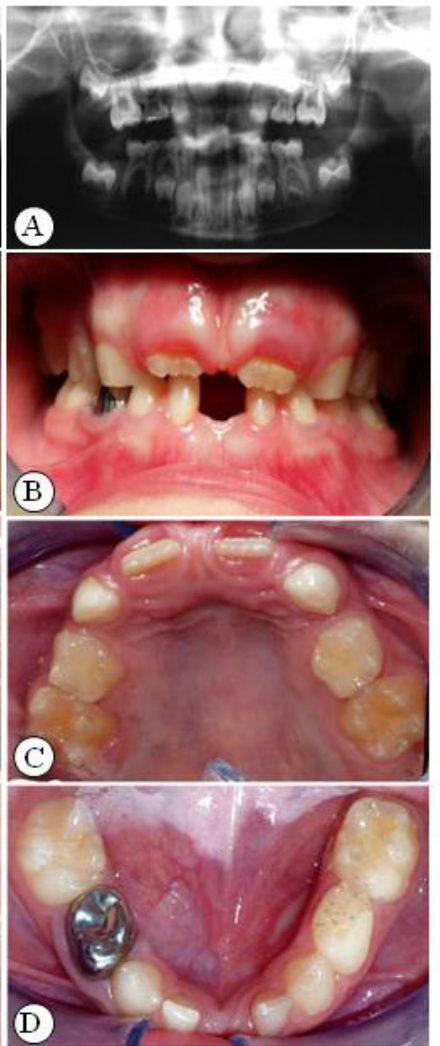

Figure 2. Clinical and radiographic oral-facial manifestation of oligodontia in the probands of each family. A. Panoramic radiograph of dentition; B. extra-oral bite photos; C-D. intra-oral dentition photos.

\section{Genotype analysis}

The sequence analysis of exons and exon-intron boundaries of the AXIN2, MSX1, and PAX9 genes in 10 members of the families revealed 11 SNPs (Table 5). These included AXIN2 c.148C $>$ T (P50S), c.1060-17C $>$ T, c.1201+69A $>$ G, c.1365A $>$ G (P455P), c.1386C $>\mathrm{T} \quad$ (P462P), c.1907+73T $>\mathrm{C}, \quad$ c.1904-18C $>\mathrm{G} ; \quad \mathrm{MSX} 1 \quad$ c.476T $>\mathrm{G}$ (L159R), c. $912+67 \mathrm{C}>\mathrm{T}$; and PAX9 c.717C $>$ T $(\mathrm{H} 239 \mathrm{H})$, and c.718G $>$ C (A240P). One novel SNP of MSX1, c.476T $>$ G (L159R), was detected in the affected and unaffected members of the families (Figure 3A), but not in healthy individuals (Figure 3B). AXIN2 P455P and P462P as well as PAX9 H239H were synonymous, whereas AXIN2 P50S, PAX9 A240P, and MSX1 L159R were missense SNPs. Four SNPs were observed in intron regions of the AXIN2 gene and may influence RNA splicing. One SNP was found in the 3' untranslated region of the MSX1 gene. Using NEBCutter V2.0, we found that these SNPs change restriction enzyme sites (Table 6). 
Table 5. Sequence variations found in AXIN2, MSX1, and PAX9.

\begin{tabular}{|c|c|c|c|c|c|c|c|c|c|c|c|c|c|}
\hline \multirow[t]{2}{*}{ Gene } & \multirow[t]{2}{*}{ Exon } & \multirow[t]{2}{*}{ Sequence variation } & \multirow[t]{2}{*}{ Amino acid change } & \multicolumn{4}{|c|}{ Family 1} & \multicolumn{6}{|c|}{ Family 2} \\
\hline & & & & $\mathrm{I}: 2$ & $\mathrm{I}: 3$ & II:1 & II:2 & III:1 & III:2 & II:2 & II:4 & $\mathrm{I}: 2$ & I:1 \\
\hline \multirow[t]{7}{*}{ AXIN2 } & 1 & c. $148 \mathrm{C}>\mathrm{T}$ & P50S & $\mathrm{CT}$ & $\mathrm{CT}$ & $\mathrm{T}$ & $\mathrm{CT}$ & $\mathrm{T}$ & $\mathrm{CT}$ & $\mathrm{CT}$ & $\mathrm{CT}$ & $\mathrm{CT}$ & CT \\
\hline & Intron 3 & c. $1060-17 \mathrm{C}>\mathrm{T}$ & & $\mathrm{CT}$ & $\mathrm{C}$ & $\mathrm{C}$ & $\mathrm{CT}$ & $\mathrm{C}$ & $\mathrm{CT}$ & $\mathrm{CT}$ & $\mathrm{C}$ & $\mathrm{CT}$ & $\mathrm{C}$ \\
\hline & Intron 4 & c. $1201+69 A>G$ & & G & $\mathrm{AG}$ & G & $\mathrm{AG}$ & G & G & G & G & G & G \\
\hline & 5 & c. $1365 \mathrm{~A}>\mathrm{G}$ & P455P & G & $\mathrm{AG}$ & G & $\mathrm{AG}$ & G & G & G & G & G & G \\
\hline & 5 & c. $1386 \mathrm{C}>\mathrm{T}$ & P462P & $\mathrm{CT}$ & $\mathrm{CT}$ & $\mathrm{T}$ & $\mathrm{CT}$ & $\mathrm{T}$ & $\mathrm{CT}$ & $\mathrm{CT}$ & $\mathrm{T}$ & $\mathrm{CT}$ & CT \\
\hline & Intron 6 & c. $1907+73 \mathrm{~T}>\mathrm{C}$ & & $\mathrm{C}$ & $\mathrm{TC}$ & $\mathrm{C}$ & $\mathrm{TC}$ & $\mathrm{C}$ & $\mathrm{TC}$ & $\mathrm{TC}$ & $\mathrm{C}$ & $\mathrm{TC}$ & $\mathrm{TC}$ \\
\hline & Intron 6 & c. $1904-18 \mathrm{C}>\mathrm{G}$ & & $\mathrm{C}$ & CG & $\mathrm{C}$ & CG & $\mathrm{C}$ & $\mathrm{C}$ & $\mathrm{C}$ & $\mathrm{C}$ & $\mathrm{C}$ & $\mathrm{C}$ \\
\hline \multirow[t]{2}{*}{ PAX9 } & 3 & c. $717 \mathrm{C}>\mathrm{T}$ & $\mathrm{H} 239 \mathrm{H}$ & $\mathrm{C}$ & $\mathrm{C}$ & $\mathrm{C}$ & $\mathrm{C}$ & $\mathrm{CT}$ & $\mathrm{CT}$ & $\mathrm{CT}$ & $\mathrm{CC}$ & $\mathrm{CC}$ & CT \\
\hline & 3 & c. $718 \mathrm{G}>\mathrm{C}$ & $\mathrm{A} 240 \mathrm{P}$ & G & G & G & G & G & G & $\mathrm{GC}$ & $\mathrm{GC}$ & $\mathrm{GC}$ & G \\
\hline \multirow[t]{2}{*}{ MSX1 } & 2 & C. $476 \mathrm{~T}>\mathrm{G}$ & L159R & TG & $\mathrm{T}$ & TG & TG & TG & TG & TG & TG & TG & TG \\
\hline & 2 & c. $912+67 \mathrm{C}>\mathrm{T}$ & Untranslated region & $\mathrm{CT}$ & $\mathrm{CT}$ & $\mathrm{C}$ & $\mathrm{C}$ & $\mathrm{CT}$ & $\mathrm{T}$ & $\mathrm{T}$ & $\mathrm{CT}$ & $\mathrm{CT}$ & $\mathrm{CT}$ \\
\hline
\end{tabular}

Table 6. Change of restriction enzyme sites of polymorphisms in AXIN2, MSX1, and PAX9.

\begin{tabular}{|c|c|c|c|c|}
\hline Gene & Exon & Sequence variation & Absent enzymes & Present new enzymes \\
\hline \multirow[t]{4}{*}{ AXIN2 } & Intron 4 & c. $1201+69 A>G$ & FatI, HpyCH4V, CviAII, NlaIII & \\
\hline & 5 & c. $1365 \mathrm{~A}>\mathrm{G}$ & PspGI, Bst NI & MspI, HpaII, NciI \\
\hline & 5 & c. $1386 \mathrm{C}>\mathrm{T}$ & Aci I & \\
\hline & Intron 4 & c. $1907+73 \mathrm{~T}>\mathrm{C}$ & & HaeIII, PhoI \\
\hline \multirow[t]{2}{*}{ MSX1 } & 2 & c. $476 \mathrm{~T}>\mathrm{G}$ & BlpI, DdeI & NlaIV \\
\hline & 2 & c. $912+67 \mathrm{C}>\mathrm{T}$ & Bsp1286I, BsiHKAI & $A f l \mathrm{III}$ \\
\hline \multirow[t]{2}{*}{ PAX9 } & 3 & c. $717 \mathrm{C}>\mathrm{T}$ & Bst $\mathrm{UI}$, DraIII & FatI, CviAII, SphI, NspI, NlaIII \\
\hline & 3 & c. $718 \mathrm{G}>\mathrm{C}$ & Cac8I, AciI, Bst $\mathrm{UI}$ & StyD4I, BssKI, ScrFI, NciI, MspI, HpaII \\
\hline
\end{tabular}

A

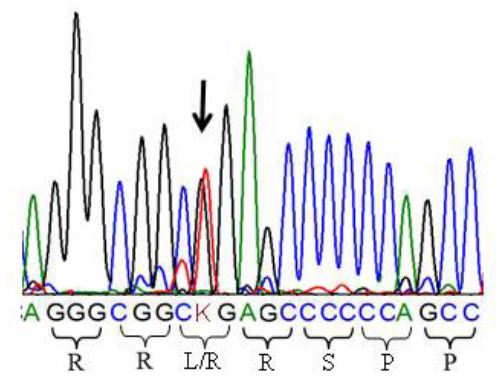

B

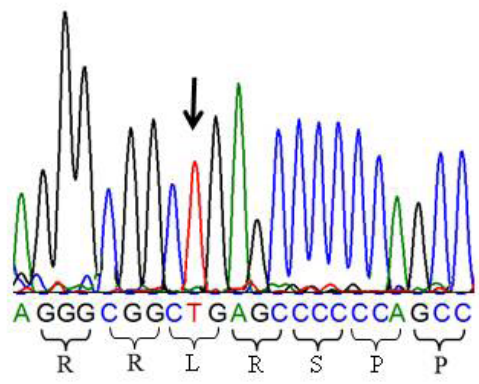

Figure 3. DNA sequencing chromatogram identified the MSX1 c.476T $>$ G polymorphism through comparison with negative controls. A. Proband III:1 in the family shows a heterozygous TG genotype of the c.476T $>$ G singlenucleotide polymorphism of the MSX1 gene. B. Healthy individual as control has the homozygous TT allele of the MSX1 gene. 


\section{Analysis of MSX1 and PAX9 protein and mRNA structures}

We predicted protein secondary structures of the MSX1 c.476 T/T (159L) and c.476 $\mathrm{G} / \mathrm{G}$ alleles (159R) using DNASIS v2.5. These results demonstrated that the protein secondary structure of the MSX1 c.476 T allele was different from that of the c.476 G allele (Figure 4A-B). Also, the substitution of the c.476 $\mathrm{T}>\mathrm{G}$ SNP changed mRNA structures and free energy (Figure 4C-D). Furthermore, the SNP of PAX9 c.718G $>$ C (A240P) altered protein and mRNA secondary structures (Figure 5A-D).
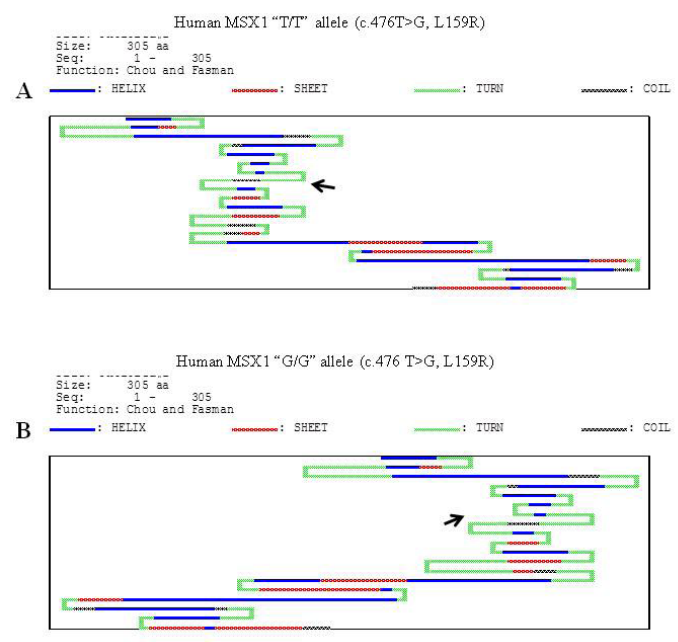

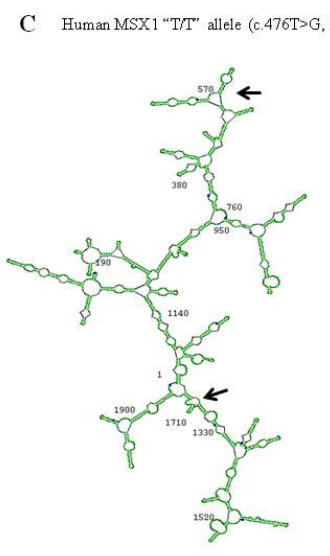

Free energy of structure $=598.6 \mathrm{kkal} / \mathrm{mol}$
D Human MSX1 “G/G" allele (c.476 T>G, L159R)

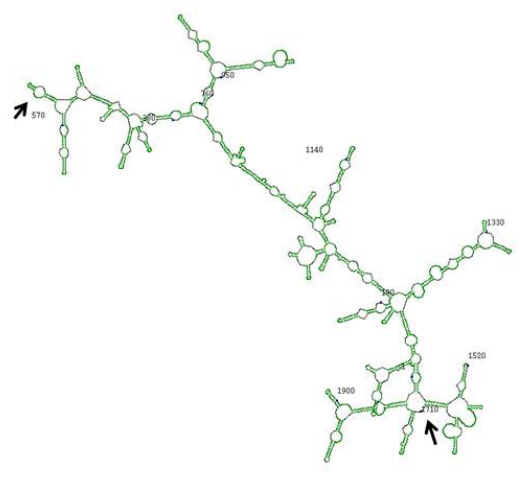

Free energy of structure $=597.8 \mathrm{kkal} / \mathrm{mol}$

Figure 4. Predicted protein and messenger RNA (mRNA) secondary structures of the MSX1 gene coding region alleles. A-B. SNP of MSX1 c.476T $>$ G (L159R). At codon 159, leucine (L) replaced by arginine (R) changes this protein secondary structure, as observe using DNASIS v2.5. C-D. The c.476T $>$ G variant also changes the mRNA secondary structure and free energy. The $\mathrm{G} / \mathrm{G}$ allele of the MSX1 c.476T $>\mathrm{G}$ is required for higher energy to form the mRNA secondary structure compared to that of the T/T allele of MSX1 c.476T $>$ G. Some differences in secondary structures between the T/T and G/G alleles of the MSX1 SNP are indicated by arrows. 
Human PAX9"G/G” allele (c.718G $>C, A 240 \mathrm{P})$

Size: $\quad 341$ aa
A Seq: 1 ia
Function: Chou and Fasman

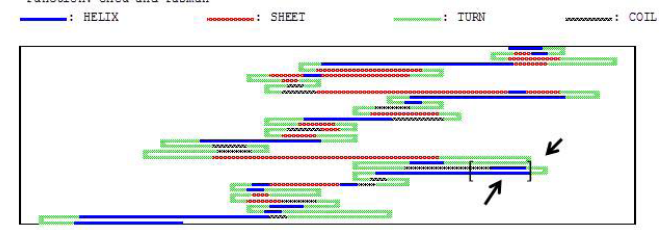

Human PAX9 “C/C" allele (c.718G>C,A240P)

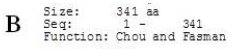

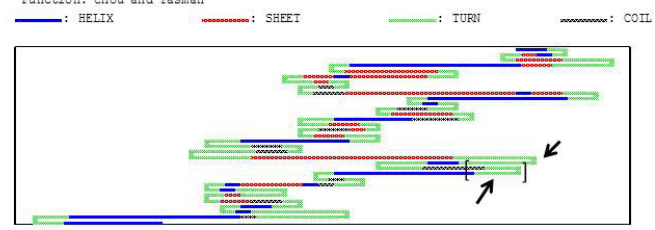

C Human PAX9"G/G” allele (c.718G>C,A240P)

D Human PAX9 “C/C"' allele (c.718G $>$ C, A240P)

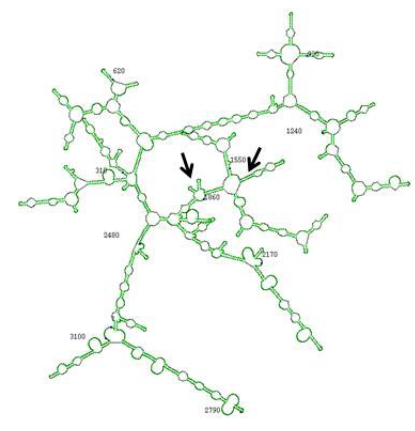

Free energy of structure $=679.5 \mathrm{kkal} / \mathrm{mol}$

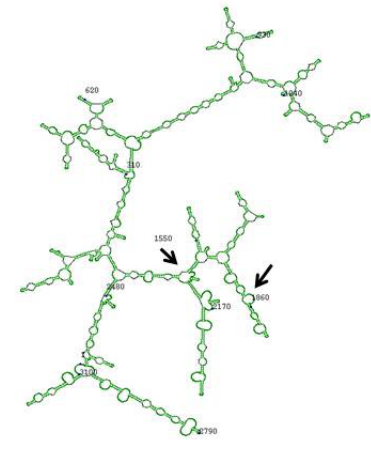

Free energy of structure $=682.2 \mathrm{kkal} / \mathrm{mol}$

Figure 5. Predicted protein and mRNA secondary structures of PAX9 coding region alleles. A.-B. SNP of PAX9 c. $718 \mathrm{G}>\mathrm{C}$ (A240P). At codon 240, alanine (A) substituted with proline (P) changes the protein secondary structure, as observed using DNASIS v2.5. The helix structure of the $\mathrm{G} / \mathrm{G}$ allele of PAX9 (c.718G $>\mathrm{C}, \mathrm{A} 240 \mathrm{P}$ ) was changed to the turn structure of the $\mathrm{C} / \mathrm{C}$ allele of PAX9 (c.718G $>\mathrm{C}, \mathrm{A} 240 \mathrm{P}$ ). The differences between the secondary structures of these PAX9 SNPs are indicated by arrows. C.-D. PAX9 c.718G $>$ C SNP also leads to changes in mRNA secondary structure and free energy. Some differences between the secondary structures of the $\mathrm{G} / \mathrm{G}$ and $\mathrm{C} / \mathrm{C}$ alleles of these PAX9 SNPs are indicated by arrows.

\section{DISCUSSION}

In this study, exons and junctions between exons and introns of the AXIN2, MSX1, and PAX9 genes were sequenced and analyzed in two Mexican families with isolated non-syndromic oligodontia. Eleven SNPs were identified in the families, including three synonymous SNPs and three missense mutations. The MSX1 c.476 T>G (L159R) and PAX9 c. 718 G $>$ C (A240P) SNPs changed protein and mRNA structures, respectively. 
Mutations of the AXIN2, MSX1, and PAX9 genes have been associated with tooth agenesis and other diseases (Vastardis et al., 1996; Stockton et al., 2000; van den Boogaard et al., 2000; Jumlongras et al., 2001; Lammi et al., 2004; Mostowska et al., 2006a; Bergendal et al., 2011). AXIN2 codes for protein downregulation of Wnt-signaling at specific stages and plays critical roles during early craniofacial development. Mutations in AXIN2 lead to the absence of most permanent molars, premolars, lower incisors, and upper lateral incisors. By contrast, the upper central incisors are always present (Mostowska et al., 2006a; Bergendal et al., 2011). In addition to oligodontia, AXIN2 mutation also predisposes individuals to colorectal cancer (Lammi et al., 2004). Recently, AXIN2 polymorphisms have been reported to be associated with a risk of hypodontia.

Callahan et al. (2009) studied 167 tooth agenesis patients from two cohorts: 116 from Rio de Janeiro, Brazil, and 55 from Turkey. The authors found that SNP c.148C >T (P50S) was significantly associated with tooth agenesis in the Brazilian cases and partly associated with haplotype in the combined Brazilian-Turkish populations with at least one missing incisor. Gunes et al. (2009) investigated 100 lung cancer patients and 100 healthy individuals in a Turkish population and found that the c.148C $>$ T (P50S) SNP had a statistically significant association with lung cancer. However, Mostowska et al. (2006a) studied 55 unrelated white patients with selective tooth agenesis and 102 healthy individuals and found no association between the AXIN2 c.148 C $>$ T (P50S) SNP and tooth agenesis, but individuals carrying the c. $956+16 \mathrm{G}$ and c. $2062 \mathrm{~T}$ alleles had an increased risk of selective tooth agenesis. Furthermore, the c.1386C $>$ T (P462P) SNP of AXIN2 has been significantly associated with astrocytoma in a Turkish population (Gunes et al., 2010). In the present study, 100\% of the studied patients carried either the CT or TT genotype of the AXIN2 c.148C $>$ T SNP and either the CT or TT alleles of the AXIN2 c.1386C $>$ T SNP, respectively. Whether the c.148C $>$ T and c.1386C $>\mathrm{T}$ variations are linked to oligodontia in the Mexican population needs to be investigated further in a large sample size.

The sequence analysis of exons and exon-intron boundaries of the MSX1 gene performed in the families revealed two polymorphisms: c. $912+67 \mathrm{C}>\mathrm{T}$, located in the untranslated region, and a novel missense variant, c.476T $>$ G, L159R. A single-nucleotide transversion from $\mathrm{T}$ to $\mathrm{G}$ in MSX1 exon 2 resulted in the replacement of leucine by arginine at codon 159. Leucine is a hydrophobic amino acid, whereas arginine is a basic amino acid. This substitution (c.476T $>$ G, L159R) changed MSX1 protein and mRNA secondary structures. The TG allele accounted for $100 \%$ of the six patients tested in the families, implying that MSX1 c.476T $>\mathrm{G}$ may be a risk factor for oligodontia in the families.

Several recent studies have shown that PAX9 polymorphisms in the promoter and coding regions might be associated with oligodontia (Kobielak et al., 2001; Peres et al., 2005). In this study, we observed two SNPs of the PAX9 gene, c. $717 \mathrm{C}>\mathrm{T}$ and $\mathrm{c} 718 \mathrm{G}>\mathrm{C}$, which have been identified in other oligodontia families (Mostowska et al., 2006b; Pawlowska et al., 2010). PAX9 c. $717 \mathrm{C}>\mathrm{T}$ is a silent mutation $(\mathrm{H} 239 \mathrm{H})$, whereas the c. $718 \mathrm{G}>\mathrm{C}$ transversion in exon 4 resulted in the replacement of alanine by proline at codon 240. Proline has a unique structure because of the bonds between its side chain and nitrogen atom of the main chain and $\alpha$-carbon. In our study, the c.718G $>$ C (A240P) variant affected mRNA and protein secondary structures. Pereira et al. (2006) have found that a common polymorphism (c.718C > T [A240P]) in the PAX9 gene is probably functional and could be associated with 3rd molar agenesis and its various distributions worldwide. The same results have been reported by Kula et al. (2008). 
Furthermore, Paixão-Cortes et al. (2011) have observed that the PAX9 A240P SNP may be related to recessive inheritance of non-syndromic dental agenesis in a Brazilian family. Furthermore, Wang et al. (2011) have found that the PAX9 A240P mutation is a risk factor for oligodontia in a Chinese Han population. Pawlowska et al. (2010) have reported that the PAX9 A240P mutation in sporadic oligodontia was polymorphic in many African, American, and European subpopulations, but the authors did not establish the presence or absence of an association between this mutation and the PAX9-associated phenotype. The discrepancy of the above results might be explained by population diversities that may cause inconsistency, as genetic polymorphisms often show ethnic variations.

Conversely, the great discrepancy between the high incidence of tooth agenesis and the relatively small number of findings implies that tooth agenesis may be a much more heterogeneous trait. The combination of two or more gene polymorphisms in tooth agenesis patients could cause changes in gene structures and protein-protein interactions as well as a reduction in gene dosages, thereby leading to specific phenotypes (Vieira et al., 2004). Pax9 and Msx1 are co-expressed during craniofacial development (Mackenzie et al., 1991; Neubuser et al., 1995). Mice with a single homozygous mutation of either the Pax9 or the Msx1 gene exhibit early arrest of tooth development (Satokata and Maas, 1994; Peters et al., 1998). In vitro studies have demonstrated that PAX9 interacting with MSX1 requires downregulated gene expression during tooth formation (Ogawa et al., 2006). In contrast to humans, mice with a heterozygous Pax9 or heterozygous Msx1 loss-of-function mutation do not display tooth formation defects, indicating that different gene dosages are required for tooth development. Recently, Nakatomi et al. (2010) have observed that a synergistic interaction between Pax9 and Msx1 in vivo is required for mouse tooth morphogenesis. The authors also found that $\mathrm{Pax}^{+/-}$and $\mathrm{Msx}^{+/-}$double heterozygous mutations interfere with incisor development during initiation, morphogenesis, and differentiation in mice. Furthermore, the expression of Shh, Bmp2, Bmp4, Fgf3, and Fgf10 genes was reduced in the teeth of these Pax9 and Msx1 double heterozygous mice.

In this study, we observed several SNPs of the MSX1 and PAX9 genes - in particular, MSX1 c.476T $>$ G (L159R) and c.718G $>$ C (A240P) - in two Mexican oligodontia family members. These SNPs changed the protein and mRNA structures of the genes. These structure variations may contribute to alterations in protein-protein interactions between PAX9 and MSX1 as well as reduce gene dosages of these proteins, thereby causing functional changes for tooth development. Our data implied that a combined reduction of PAX9 and MSX1 gene dosage may be a risk factor for tooth agenesis. However, the confirmation of genotype dosages/phenotype corrections requires additional research.

\section{ACKNOWLEDGMENTS}

Research supported by grants from the National Institute of Dental and Craniofacial Research (\#DE019892).

\section{REFERENCES}

Bergendal B, Klar J, Stecksen-Blicks C, Norderyd J, et al. (2011). Isolated oligodontia associated with mutations in EDARADD, AXIN2, MSX1, and PAX9 genes. Am. J. Med. Genet. A 155A: 1616-1622.

Callahan N, Modesto A, Meira R, Seymen F, et al. (2009). Axis inhibition protein 2 (AXIN2) polymorphisms and tooth 
agenesis. Arch. Oral Biol. 54: 45-49.

Chishti MS, Muhammad D, Haider M and Ahmad W (2006). A novel missense mutation in MSX1 underlies autosomal recessive oligodontia with associated dental anomalies in Pakistani families. J. Hum. Genet. 51: 872-878.

Das P, Hai M, Elcock C, Leal SM, et al. (2003). Novel missense mutations and a 288-bp exonic insertion in PAX9 in families with autosomal dominant hypodontia. Am. J. Med. Genet. A 118A: 35-42.

De Muynck S, Schollen E, Matthijs G, Verdonck A, et al. (2004). A novel MSX1 mutation in hypodontia. Am. J. Med. Genet. A 128A: 401-403.

Frazier-Bowers SA, Guo DC, Cavender A, Xue L, et al. (2002). A novel mutation in human PAX9 causes molar oligodontia. J. Dent. Res. 81: 129-133.

Gabris K, Tarjan I, Csiki P, Konrad F, et al. (2001). Prevalence of congenital hypodontia in the permanent dentition and its treatment. Fogorv. Sz. 94: 137-140.

Gunes EG, Pinarbasi E, Pinarbasi H and Silig Y (2009). Strong association between lung cancer and the AXIN2 polymorphism. Mol. Med. Rep. 2: 1029-1035.

Gunes EG, Pinarbasi E and Pinarbasi H (2010). AXIN2 polymorphism and its association with astrocytoma in a Turkish population. Mol. Med. Rep. 3: 705-709.

Jumlongras D, Bei M, Stimson JM, Wang WF, et al. (2001). A nonsense mutation in MSX1 causes Witkop syndrome. Am. J. Hum. Genet. 69: 67-74.

Jumlongras D, Lin JY, Chapra A, Seidman CE, et al. (2004). A novel missense mutation in the paired domain of PAX9 causes non-syndromic oligodontia. Hum. Genet. 114: 242-249.

Kapadia H, Frazier-Bowers S, Ogawa T and D'Souza RN (2006). Molecular characterization of a novel PAX9 missense mutation causing posterior tooth agenesis. Eur. J. Hum. Genet. 14: 403-409.

Kim JW, Simmer JP, Lin BP and Hu JC (2006). Novel MSX1 frameshift causes autosomal-dominant oligodontia. J. Dent. Res. 85: 267-271.

Klein ML, Nieminen P, Lammi L, Niebuhr E, et al. (2005). Novel mutation of the initiation codon of PAX9 causes oligodontia. J. Dent. Res. 84: 43-47.

Kobielak A, Kobielak K, Wisniewski AS, Mostowska A, et al. (2001). The novel polymorphic variants within the paired box of the PAX9 gene are associated with selective tooth agenesis. Folia Histochem. Cytobiol. 39: 111-112.

Kula K, Trimmell J, Lu Y, Briscoe P, et al. (2008). Tooth agenesis in a family and homozygous PAX9 mutation in exon 3: a case report. World J. Orthod. 9: e55-e61.

Lammi L, Arte S, Somer M, Jarvinen H, et al. (2004). Mutations in AXIN2 cause familial tooth agenesis and predispose to colorectal cancer. Am. J. Hum. Genet. 74: 1043-1050.

Lidral AC and Reising BC (2002). The role of MSX1 in human tooth agenesis. J. Dent. Res. 81: 274-278.

Mackenzie A, Leeming GL, Jowett AK, Ferguson MW, et al. (1991). The homeobox gene Hox 7.1 has specific regional and temporal expression patterns during early murine craniofacial embryogenesis, especially tooth development in vivo and in vitro. Development 111: 269-285.

Mostowska A, Biedziak B and Jagodzinski PP (2006a). Axis inhibition protein 2 (AXIN2) polymorphisms may be a risk factor for selective tooth agenesis. J. Hum. Genet. 51: 262-266.

Mostowska A, Biedziak B and Trzeciak WH (2006b). A novel c.581C $>$ T transition localized in a highly conserved homeobox sequence of MSX1: is it responsible for oligodontia? J. Appl. Genet. 47: 159-164.

Nakatomi M, Wang XP, Key D, Lund JJ, et al. (2010). Genetic interactions between Pax9 and Msx1 regulate lip development and several stages of tooth morphogenesis. Dev. Biol. 340: 438-449.

Neubuser A, Koseki H and Balling R (1995). Characterization and developmental expression of Pax9, a paired-boxcontaining gene related to Pax1. Dev. Biol. 170: 701-716.

Nieminen P, Pekkanen M, Aberg T and Thesleff I (1998). A graphical WWW-database on gene expression in tooth. Eur. J. Oral Sci. 106 (Suppl 1): 7-11.

Ogawa T, Kapadia H, Feng JQ, Raghow R, et al. (2006). Functional consequences of interactions between Pax9 and Msx1 genes in normal and abnormal tooth development. J. Biol. Chem. 281: 18363-18369.

Paixão-Cortes VR, Braga T, Salzano FM, Mundstock K, et al. (2011). PAX9 and MSX1 transcription factor genes in nonsyndromic dental agenesis. Arch. Oral Biol. 56: 337-344.

Pawlowska E, Janik-Papis K, Poplawski T, Blasiak J, et al. (2010). Mutations in the PAX9 gene in sporadic oligodontia. Orthod. Craniofac. Res. 13: 142-152.

Pereira TV, Salzano FM, Mostowska A, Trzeciak WH, et al. (2006). Natural selection and molecular evolution in primate PAX9 gene, a major determinant of tooth development. Proc. Natl. Acad. Sci. U. S. A. 103: 5676-5681.

Peres RC, Scarel-Caminaga RM, do Espírito Santo AR and Line SR (2005). Association between PAX-9 promoter polymorphisms and hypodontia in humans. Arch. Oral Biol. 50: 861-871.

Peters H, Neubuser A, Kratochwil K and Balling R (1998). Pax9-deficient mice lack pharyngeal pouch derivatives and 
teeth and exhibit craniofacial and limb abnormalities. Genes Dev. 12: 2735-2747.

Satokata I and Maas R (1994). Msx1 deficient mice exhibit cleft palate and abnormalities of craniofacial and tooth development. Nat. Genet. 6: 348-356.

Schalk-van der Weide Y, Steen WH and Bosman F (1992). Distribution of missing teeth and tooth morphology in patients with oligodontia. ASDC J. Dent. Child 59: 133-140.

Stockton DW, Das P, Goldenberg M, D'Souza RN, et al. (2000). Mutation of PAX9 is associated with oligodontia. Nat. Genet. 24: 18-19.

Suda N, Ogawa T, Kojima T, Saito C, et al. (2011). Non-syndromic oligodontia with a novel mutation of PAX9. J. Dent. Res. 90: 382-386.

Tallon-Walton V, Manzanares-Cespedes MC, Arte S, Carvalho-Lobato P, et al. (2007). Identification of a novel mutation in the PAX9 gene in a family affected by oligodontia and other dental anomalies. Eur. J. Oral Sci. 115: 427-432.

Thesleff I and Sharpe P (1997). Signalling networks regulating dental development. Mech. Dev. 67: 111-123.

van den Boogaard MJ, Dorland M, Beemer FA and van Amstel HK (2000). MSX1 mutation is associated with orofacial clefting and tooth agenesis in humans. Nat. Genet. 24: 342-343.

Vastardis H, Karimbux N, Guthua SW, Seidman JG, et al. (1996). A human MSX1 homeodomain missense mutation causes selective tooth agenesis. Nat. Genet. 13: 417-421.

Vieira AR, Meira R, Modesto A and Murray JC (2004). MSX1, PAX9, and TGFA contribute to tooth agenesis in humans. J. Dent. Res. 83: 723-727.

Wang J, Jian F, Chen J, Wang H, et al. (2011). Sequence analysis of PAX9, MSX1 and AXIN2 genes in a Chinese oligodontia family. Arch. Oral Biol. 56: 1027-1034. 